\title{
Towards a General Framework For Business Tests
}

\author{
Marijke Swennen $^{1}$, Benoît Depaire ${ }^{1,2}$, Koen Vanhoof $^{1}$ and Mieke Jans ${ }^{1}$ \\ ${ }^{1}$ Business informatics research group, Hasselt University, Agoralaan Building D, 3590 Diepenbeek, Belgium \\ ${ }^{2}$ Research Foundation Flanders (FWO), Egmontstraat 5, 1000 Brussels, Belgium \\ \{marijke.swennen,benoit.depaire,koen.vanhoof,mieke.jans\}@uhasselt.be
}

Keywords: $\quad$ Business Test, Problem Definition, Performance, Compliance, Risk, Design Science.

\begin{abstract}
Testing and controlling business processes, activities, data and results is becoming increasingly important for companies. Based on the literature, business tests can be divided into three domains, i.e. performance, risk and compliance and separate domain-specific frameworks have been developed. These different domains and frameworks hint at some aspects that need to be taken into account when managing business tests in a company. In this paper we identify the most important concepts concerning business tests and their management and we provide a first conceptual business test model. We do this based on an archival research study in which we analyse business tests performed by an international consultancy company.
\end{abstract}

\section{INTRODUCTION}

In classical management theory, Fayol (1949) identified five 'elements' of management, among which Controlling is one. While the validity of Fayol's work has been subject of academic debate (Fells, 2000), there is little arguing that companies are increasingly confronted with incentives and obligations to test and control their business (Wade and Recardo, 2001; Shamsaei et al., 2010). These business tests entail any kind of test on business objects such as a process, an activity, an employee or a product.

The need for business testing stems from different origins, such as legislation compliance requirements, Service Level Agreements (SLAs) or performance management (Wade and Recardo, 2001). We argue that due to the diverse nature of business test incentives, management of business tests is often without a holistic overview, fragmented and as a consequence possibly inefficient.

The objective of this paper is threefold: we provide a rationale for a consolidated view of business tests, a working definition of business tests and identify various dimensions of business tests. This research is a first step towards a general framework to identify, model and manage business tests.

Section 2 and 3 will respectively describe the applied research methodology and the data, while section 4 introduces the rationale for a consolidated business test framework. Next, section 5 will discuss the definition and several dimensions of business tests. Conclusions and future work will be discussed in section 6 .

\section{RESEARCH METHODOLOGY}

The research described in this paper is part of a bigger research project with the objective to develop models, methods and a language for a holistic business test framework. The nature of these overall research objectives demand for the scientific paradigm of Design Science research (Hevner et al., 2004, Peffers et al., 2007). This paper presents the first steps of this paradigm, i.e. the problem identification, the research motivation and a first iteration to define a business test artefact.

All results were derived through literature review and archival research. Firstly, a literature review of existing work on business tests was performed according to the steps by Fink (2005). Based on the gained insights, the business test artefact was developed.

Next, archival research on a set of 156 business tests, provided by 4 different business units of an international consultancy company, was performed to evaluate to what extent the different elements of a business test artefact can and have been applied. 
The archival research findings were further enriched by qualitative interviews with various employees actively working with business tests at different levels in the business test cycle, such as developing, implementing, performing, evaluating and improving business tests. The seven stages of conducting interviews, stated by Kvale and Brinkmann (2008), were applied.

\section{DATA}

For our archival research study, we selected an international consultancy company as our case study as it consists of different business units performing business tests for different reasons. In total 4 units were selected, i.e. Audit \& Risk, Forensics, Tax and Consulting, from which a convenience sample of 156 was drawn. Please note the exploratory nature of this research which justifies the use of a convenience sample.

The tests performed in the first business unit, Audit \& Risk, define the risk level of a client company. The second business unit performs all tests related to Forensics, which concerns the risk and compliance level of a company. Tax is a business unit in which all kinds of tests concerning VAT and applied VAT rates are performed. These are defined as compliance tests that result from rules or laws the client companies need to obey to. Finally, the Consulting business unit performs tests to provide advice to client companies about different elements such as pricing or customer orientation. These tests can be categorized as performance tests.

The number of tests performed by each business unit, is given in table 1 .

Table 1: Overview of all tests per business unit in the case study.

\begin{tabular}{|l|l|}
\hline Business Unit & Number of tests \\
\hline Audit \& Risk & 31 \\
\hline Forensics & 75 \\
\hline Tax & 36 \\
\hline Consulting & 14 \\
\hline Total & 156 \\
\hline
\end{tabular}

\section{AN INTEGRATED BUSINESS TEST FRAMEWORK}

Research on business tests has been done in three business domains, i.e. performance management, compliance management and risk management. Within each domain, several separate models and frameworks have been developed. For a comprehensive overview of trends and different frameworks in each domain, the reader is respectively referred to Bourne (2001) or Bititci et al. (2011), Mahmoud (2010) and O'Donnell (2005).

The fact that each research domain presents its own frameworks is also reflected in the business reality where an integrated approach towards business tests is often lacking. Although each business unit of the company in our archival research study identifies its tests as exclusively related to either performance, compliance or risk, some tests can actually be assigned to multiple domains. However, two lines of arguments can be developed in favour of a more integrated approach.

Firstly, from a management perspective, isolating business test efforts from each other, could lead to inefficiencies. Shamsaei et al. (2010) mention that different business rules might be correlated and actions to improve the results for one rule might have side effects on other rules. Being unaware of such correlations leads to suboptimisation. Also, measuring and evaluating highly similar and even duplicate tests for different perspectives, will create an administrative burden.

Furthermore, Bardoliwalla et al. (2009) state that risk management is often hampered by organizational silos, causing a lack of consistent taxonomies, measurement, and reporting. This results in obscured visibility, preventing managers to obtain a true picture of the overall enterprise. It is expected that their observation gains even more importance when expanding to the full range of business tests.

A second line of arguments in favour of an integrated business test framework originates from the information systems perspective. Business tests deal with measuring and gathering the correct data and providing it timely to the right manager, preferably in an automated way. Consequently, business tests should be an integrated part of the information architecture and have a direct impact on the data and system requirements. Strangely, while several frameworks, models and languages exist to provide an overview of the data architecture and the business process architecture, no such framework exists for business tests. Consequently, if a manager asks the IT department for the implementation of a 
new business test, the development team lacks a complete overview of the existing business tests.

The idea of an integrated approach is not entirely new and recently a few researchers have hinted at a similar idea. A first attempt is the GRC concept, which combines governance with risk and compliance management and is an emerging topic in the business domain (Racz et al., 2010). Bardoliwalla et al. (2009) further combine the GRC concept with performance management, merging the main three sources of business tests. While the work of Bardoliwalla et al. (2009) unifies the three concepts of performance, risk and compliance into a coherent strategic management process framework, they do not provide an integrated framework how to design, implement and document business tests.

\section{THE CONCEPTUAL MODEL FOR A BUSINESS TEST}

A test can be defined as the evaluation of a measurement against a predefined target, where the evaluation process results in a conclusion about the measured object.

For example, to test whether we should stop at the current gas station entails measuring the current fuel level and evaluating it against the fuel level target required to drive to the next gas station. Based on this evaluation we can conclude if we make it to the next station.

A Business Test is then a test that relates to any kind of business object, such as e.g. a product or process, and is typically related to some kind of performance, risk or compliance purpose (or a combination of them as we discussed in section 4). Note that we define a business test at the lowest (most detailed) measurement level.

With this general definition of a business test, we proceeded to analyse the literature to develop a conceptual model for a business test, which is illustrated in Figure 1. We identified concepts from the performance, compliance and risk literature that were relevant to a general business test concept. Next, archival research evaluated if the different elements of a business test made sense in practice. Simultaneously, we explored to what extent our set of business tests were complete in the sense of our conceptual model.

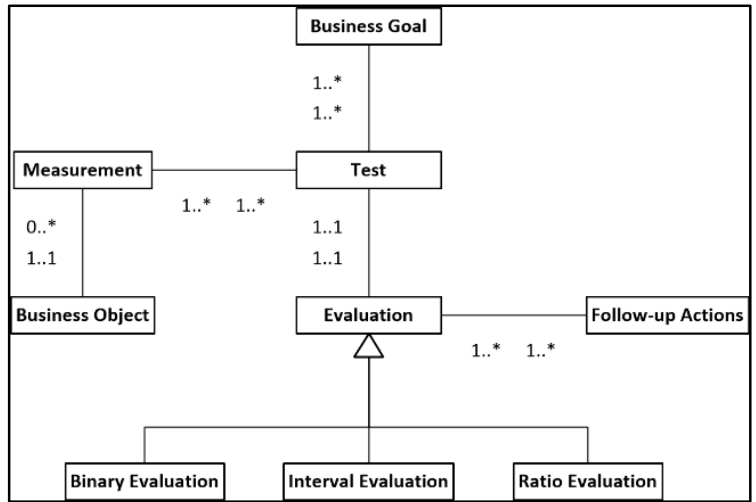

Figure 1. The conceptual model of a business test.

\subsection{Business Object}

From our conceptual model in Figure 1 we can argue that a business test should always be indirectly linked to a business object via a measurement. A measurement is an observation of a business object, i.e. the number of steps in a process or the average weight of a specific product, but is never a comparison between two things, which is the evaluation. A measurement is always related to only one object but more than one measurement can be necessary to perform a test. As a result, a single business test can be concerned with several business objects which means that several business tests may be required to evaluate a specific aspect of the company. The evaluation is the formula or metric and the target with which the measured value will be compared to define a conclusion.

For almost all business tests performed at the international consultancy company a link with a business object can be found. The Forensics and Consulting business units, for example, both define eleven business tests to check the quality of master data of a client company. This implies that different tests are performed to evaluate the quality of master data. Furthermore, in the Audit \& Risk business unit, all tests perform a check on data from the purchasing process in client companies. For each test a certain measure of this process is stored. To conclude we can state that for almost all tests at the different business units of our case study company a link to a business object is defined.

\subsection{Business Goal}

One of the frameworks in the performance measurement domain, defined by Neely et al. (2000), states that performance measures should always be 
linked to the company's strategic objectives. Following this thought, we can argue that business tests should be connected to one or more business objectives or goals and that these goals should be properly documented.

Most of the tests in the different lists of our archival research do not include any objective or goal. Only the list of tests from the Forensics business unit includes for every set of tests an objective. However, after analysis, these objectives are found to be explanations of how the tests will be performed and cannot be regarded as business goals. For example, for the quality of master data tests, the given objective is to identify missing critical master data for customers and suppliers. This only gives an overview of the different checks that will be performed. From this we can conclude that the objectives of the business tests in our sample are not documented. Some additional questions at the consultancy company tell us that the overall goal of the different business units is to make sure the client company is satisfied with the delivered service. Furthermore, the interviews tell us that at Audit \& Risk the objectives are mostly to look for fraud and irregularities in client data. This is something they only started documenting very recently and is not standardized or implemented yet.

\subsection{Evaluation scales}

We defined a test as the evaluation of a measurement against a predefined target, where the evaluation process results in a conclusion about the measured object. The risk management framework developed by Kaplan and Mikes (2012) presents a categorization of risks that allows to tell which actions to take for and how to evaluate each risk category. The first category are preventable risks, which arise from within the organization. They are controllable, should be eliminated or avoided and are best managed through active prevention. This implies a binary evaluation, the risk should be corrected immediately if it occurs.

Category two are strategy risks that are quite different from preventable risks because they can be assumed to be not inherently undesirable. Sometimes it is required to take on significant risks, and managing those risks can be an important factor in obtaining potential benefits. A risk management system is required to reduce the probability that the assumed risks occur and to improve the ability to contain or monitor the ratio between performance and risk. Here a ratio evaluation is implied which requires measurements of different objects.
The third category are risks which arise from events outside the company and are therefore beyond its influence or control. Causes may be natural or political disasters and major macroeconomic shifts. With an interval evaluation management should focus on measuring and mitigating the impact of these risks because they cannot be prevented from occurring.

At the Tax business unit all tests are evaluated with 'ok' or 'not ok'. This implies no toleration or trade-off for the results of these tests. In the list of tests from Forensics, some guidance steps for the client company are provided in case risky or unreliable results occur. All test results are evaluated by checking their importance or impact, which implies a ratio evaluation. From this we can conclude that for some business units of our archival research company a notion of ways to evaluate the results is present. However, this is only true for two of the four business units in the study.

\subsection{Follow-up actions}

Based on the different categories of risk presented in the risk management framework of Kaplan and Mikes (2012), we can argue that all categories have one thing in common. For a proper management of risks not only measuring their impact is of importance, also the identification of which actions to take in mitigating or managing these risks should be included. This refers to the conclusion in our general definition of a business test. We can transfer this idea to the business concept by stating that for every business test the possible follow-up actions and triggers to activate these actions should be defined. Based on the three types of risks, we see that different types of risks can have a different influence on how each test should be evaluated and which follow-up action should be performed. We can add the notion that a follow-up action of a business test can be another business tests. This is also discussed in section 5.6.

In the Forensics and Tax business units we find that for only a small amount of tests follow-up actions are included. At Tax, most of the defined follow-up actions are manual checks or the delivery of a list of transactions with standout results to the client company. In five of the tests performed by the Tax business unit a business test is followed by another business test if a certain result occurs. However, there is no documentation about which actions to take to prevent, manage or mitigate certain risk events. 


\subsection{Weights}

In the compliance management domain we find the approach developed by Shamsaei et al. (2010) which enables organizations to measure the current compliance level of their processes and track down and analyse compliance problems. Measuring the importance of organizational rules allows to distinguish the most important problems that need to be assigned first from the less important problems. By expanding these conclusions to the business test concept, we can argue that giving weights to business tests can provide an insight in which tests and which resulting outcomes need to be covered first. Moreover, an overall measure of compliance can be found by providing more important tests with a higher weight.

The notion of different weights given to business tests could not be found in the lists of business tests we received from the different business units of the consulting company. The tests are presented as being all at the same level, implying that they all have the same weight or importance. Some additional questions at the company tell us that these weights and their documentation appear to be interesting but are not yet developed or implemented.

\subsection{Intertest Relationships}

Besides the notion of weights, Shamsaei et al. (2010) also argue that more than one rule possibly applies to a single process, and hence a change to enhance the compliance level of one rule may have side effects on the compliance level of other rules. Transferred to the concept of business tests, we can argue that the result or outcome of a business test can be influenced by the implementation or the result of another business test. This adds to the findings that business tests can be follow-up actions of other business tests. In the conceptual model in Figure 1, this interest relationship is indirectly given by the many-to-many relationship between objects and tests. The business objects represent the link between different business tests.

We already mentioned that some business tests from the international consulting company are followed by other business tests, but there is no information about the influence of different business tests and their results on each other.

\section{CONCLUSIONS}

From the literature review we can infer that the different business test domains, i.e. performance, compliance and risk, are only recently brought in connection to each other. Most existing frameworks concern only one of these domains. However, in this research we found that some business tests are not exclusively assignable to just one of these domains. Furthermore, we noticed that in many cases, business testing and the management of these tests fall victim to organizational silos, lacking consistent taxonomies, measurement, and reporting, which obscures visibility.

In this first step of our overarching research project to develop a holistic business test framework we define a business test as an evaluation of a measurement against a predefined target, where the evaluation process results in a conclusion about the measured object. Furthermore we state that business tests are grouped around a business object and connected to a higher business objective. The evaluation scale, weight and follow-up actions, which can be other business tests, should be defined and intertest relationships may be present.

The need for a proper management of business tests becomes clearer when adding the findings from the archival research study. In this study we found that the objectives of the business tests are not documented properly and that no weights are provided to the business tests as suggested by the literature. Besides that, only a small amount of the tests in the study include a notion of follow-up actions and ways to evaluate the results of the tests. However, most of the tests can be divided in different groups around objects in the company. Finally, we can conclude that valuable information is trapped in the different departments of the organization and is not aggregated with information from other departments. Especially for the steps before actually performing the tests, the data collection and data cleaning, a lot of redundancy is present

In general, these results empirically validate the need for an integrated framework for defining and implementing business tests, as only some of the business test elements are present.

After performing this first step in the Design Science Research Methodology Cycle, the next steps can be executed. In cooperation with some experts working with the business tests in our archival research the tests can be transferred into our conceptual model. Appropriate enhancements or modifications can be implemented. 
However some challenges and different perspectives can provide an even better basis for this first step. First of all, we can assume that different companies can be in a different maturity level in terms of the development and implementation of business tests and the structure of business tests. Also, the same research can be carried out on tests performed at companies on their own data instead of consultancy companies who perform tests at client data.

\section{REFERENCES}

Bardoliwalla, N., Buscemi, S., Broady, D., 2009. Driven to Perform: Risk-Aware Performance Management From Strategy Through Execution. Evolved Technologist Press. New York, $1^{\text {st }}$ edition.

Bititci, U, Garengo, P., Dorfler, V., Nudurupati, S., 2011. Performance measurement: challenges for tomorrow. In International Journal of Management Reviews 14 (3). p. 305-327.

Bourne, M., 2001. Handbook of Performance Measurement. Gee Publishing Limited, London.

Fayol, H., 1949. General and Industrial Management. Sir Isaac Pitman \& Sons Ltd. London.

Fells, M. J., 2000. Fayol stands the test of time. In Journal of Management History, 6 (8), p. 345-360.

Fink, A., 2005. Conducting Research Literature Reviews. From the Internet to Paper. Sage Publications. $2^{\text {nd }}$ edition.

Hevner, A.R., March, S.T., Park, J., Ram, S., 2004. Design Science in Information Systems Research, In MIS Quarterly, 28 (1), p. 75-105.

Kaplan, R. S., Mikes, A., 2012. Managing Risks: A New Framework. In Harvard Business Review. 90 (6), p. 4860.

Kvale, S., Brinkmann, S., 2008. InterViews: Learning the Craft of Qualitative Research Interviewing. SAGE Publications, Inc.

Mahmoud, A., 2010. A compliance management framework for business process models. Ph.D. Thesis. Germany, University of Potsdam.

Neely, A., Bourne, M. Kennerley, M., 2000. Performance measurement system design: developing and testing a process-based approach. In International Journal of Operations \& Production Management. 20 (10). p. 1119-1145.

O'Donnell, E., 2005. Enterprise risk management: A system-thinking framework for the event identification phase. In International Journal of Accounting Information Systems. 6 (3). p. 177-195.

Peffers, K., Tuunanen, T., Rothenberger, M., Chatterjee, S., 2007. A Design Science Research Methodology for Information Systems Research, Journal of Management Information Systems. 24 (3). p. 45-77.

Racz, N., Weippl, E., \& Seufert, A., 2010. A frame of reference for research of integrated governance, risk and compliance (GRC). In Communications and Multimedia Security, p. 106-117.

Shamsaei, A., Pourshahid, A., Amyot, D., 2010. Business Process Compliance Tracking Using Key Performance Indicators. In 6th Int. Workshop on Business Process Design (BPD 2010), BPM 2010 Workshops, LNBIP 66, Springer, p. 73-84

Wade, D., Recardo, R., 2001. Corporate Performance Management: How to build a better organization through measurement-driven, strategic alignment. Butterworth-Heinemann. 